\title{
Locked-in or Locked-out: Can a Public Services Market Really Change?
}

\author{
MARK CONSIDINE*, SIOBHAN O'SULLIVAN**, MICHAEL MCGANN*** iD \\ AND PHUC NGUYEN**** \\ *Chancellery, Raymond Priestly Building, University of Melbourne, Parkville 3010, Australia. \\ email: m.considine@unimelb.edu.au \\ ** School of Social Sciences, Morven Brown Building C20, University of New South Wales, \\ NSW 2052, Australia \\ email: siobhan.osullivan@unsw.edu.au \\ *** School of Social and Political Sciences, University of Melbourne, Parkville 3010, Australia \\ email: mmcgann@unimelb.edu.au \\ ****k La Trobe Business School, La Trobe University Shepparton Campus, 210 Fryers Street, \\ Shepparton 3630, Australia \\ email: p.nguyen2@latrobe.edu.au
}

\begin{abstract}
Australia's welfare-to-work system has been subject to ongoing political contestation and policy reform since the 1990s. In this paper we take a big picture look at the Australian system over time, re-visiting our earlier analysis of the impact of marketisation on flexibility at the frontline over the first ten years of the Australian market in employment services. That analysis demonstrated that marketisation had failed to deliver the service flexibility intended through contracting-out, and had instead produced market herding around a common set of standardised frontline practices. In the interim, there have been two further major redesigns of the Australian system at considerable expense to taxpayers. Re-introducing greater flexibility and service tailoring into the market has been a key aim of these reforms. Calling on evidence from an original, longitudinal survey of frontline employment service staff run in 2008, 2012 and 2016, this paper considers how the Australian market has evolved over its second decade. We find remarkable consistency over time and, indeed, evidence of deepening organisational convergence. We conclude that, once in motion, isomorphic pressures towards standardisation quickly get locked into quasi-market regimes; at least when these pressures occur in low-trust contracting environments.
\end{abstract}

Keywords: quasi-markets; isomorphism; contracting-out; marketisation; welfare-towork; tailoring

\section{Introduction}

Since the 1990s, there has been a radical change in the institutions delivering public employment services in many OECD countries. Nowhere has this been more apparent than in Australia which, in ten years, went from a publicly delivered employment services regime, to a system of shared delivery between the public and private sectors, to an entirely privatised system of market 
delivery. These institutional changes have involved a fundamental shift in the role of the government from a provider to a purchaser of services, driven by a set of principal-agent assumptions about the ability of contracts to mitigate information asymmetry problems in public service supply chains, and the conviction that marketisation can produce a system that is not only more efficient but also 'more tailored, more personalised, and more flexible' (Considine et al., 2015: 46). This was the underlying logic behind the introduction of Australia's Job Network (JN), an 'internationally important social policy experiment' (Ramia and Carney, 2000: 60) in competitive tendering that operated from 1998 until 2009.

Successive Australian governments have shown no loss of appetite for continued service market experimentation. Along with periodic contracting rounds, there have been two major system re-structures: Job Services Australia (2009) and Jobactive (2015), each designed to address identified shortcomings of their predecessors. Frequently these related to the inability of successive market models to produce services that were flexibly tailored to the long-term unemployed; criticisms frequently levelled against JN (Bredgaard and Larsen, 2008; Finn, 2011; McDonald and Marston, 2008; Ramia and Carney, 2010). In a study drawing on comparative survey research with frontline employment services staff in the late 1990s and 2008, Considine et al. (2011) concluded that JN had evolved into a highly standardised system, as providers adopted increasingly conservative and converging practices over time.

In this paper, we examine this second decade of Australian quasi-market reform and the changes that have unfolded since JN. Drawing on two further waves of data collection from frontline staff in 2012 and 2016 and comparing these to the earlier study of frontline service delivery under JN, we consider whether more recent restructures have been able to arrest the previously documented trends towards service standardisation and provider herding that appeared to have set in by the end of JN. Or have such features become indelibly 'locked-in' to the Australian welfare market?

In developing this analysis, we draw on the concept of institutional isomorphism from organisational theory (DiMaggio and Powell, 1983; Beckert, 2010), as well as insights from quasi-markets and transaction cost theory concerning the effects of different transaction modes on competition and quality (for example Greer et al., 2017; Bennett, 2017; Bartlett, 1991), to examine the dynamics of change within employment services fields and the extent to which such public services markets can be expected to evolve into more varied systems or consolidate around a set of 'dominant organisational models' (DiMaggio and Powell, 1983: 148). Theorists predict that public service organisations are particularly susceptible to isomorphism, or convergence towards similar organisational structures and processes, due to their resource dependency and accountability relationships to government (Frumkin and Galaskiewicz, 2004); features that, 
we argue, apply equally to non-government organisations in publicly-funded welfare markets. Indeed, aspects of how the transactional arrangements between purchasers and providers are organised in welfare markets can further strengthen and intersect with these isomorphic pressures to reinforce tendencies towards standardisation in employment services fields. These include the structure of the pricing mechanism, the level of prescription in contracts, the high barriers to entry facing new entrants and uncertainty over the relationship between provider inputs and client outcomes; conditions that incentivise organisations to replicate what others already do - but to try to do so more efficiently - while shielding established providers from new competitors with alternative organisational processes.

In what follows, we introduce the concept of institutional isomorphism and how it relates to understanding patterns of development and change within public services markets. We then review the key design features and evolution of Australia's JN, and subsequent attempts to reform Australia's marketised system towards greater flexibility, before introducing the present study and our findings.

\section{Isomorphism in organisational fields}

New theories of public management posit that the creation of quasi-markets will enhance diversity in service delivery as agencies strive to innovate to gain competitive adavantage. They view the competitive drive for efficiency as the catalyst of institutional change, as in the example of Payment-by-Results contracts which rely on the performance signals in payment models to motivate agencies to 'develop new practices to identify and tackle individual employment barriers' (Finn, 2012: 24). For organisational theorists in sociology, however, it is the demand for legitimacy rather than efficiency that is 'the major driving force of organisational change' (Knill and Balint, 2008: 679), and which drives organisations within shared fields of action to become 'more similar without necessarily making them more efficient' (DiMaggio and Powell, 1983: 147). Over time, organisations exposed to similar conditions converge on 'similar norms, structures and systems' (Kitchener, 1998: 75) as they adapt 'to conform to the expectations of the key stakeholders in their environment' (Ashworth et al., 2007: 165).

DiMaggio and Powell (1983) identify distinct coercive, mimetic, and normative isomorphic mechanisms. For example, organisations may adapt because they are pushed into doing so by organisations they depend upon, such as governments. Governments can coerce organisations to adjust their structures through their 'power to regulate' (Frumkin and Galaskiewicz, 2004: 284) but also through their control over funding (Ashworth et al., 2007). In such cases of coercive isomorphism, diffusion occurs through defensive reactions to 
systems of administrative accountability, as organisations comply with institutional pressures to adopt 'those routines and structures that are defined by law or government agencies as legitimate' (Frumkin and Galaskiewicz, 2004: 286). Eligibility requirements for government contracts, for example, may push organisations within a given field to adopt similar financial reporting and governance processes. Kitchener's (1998) study of quasi-market transformation among UK hospitals showed how representative bodies informally exerted pressures on hospital managers to adopt a clinical directorates organisational structure, which then became the archetypal UK hospital model despite never being mandated as policy. In the context of the Australian welfare market, previous studies have highlighted the pressures exerted on not-for-profits to professionalise and reform their boards in order to maintain exchange relationships with government (Considine et al., 2014b).

In public services markets characterised by a purchaser-provider split, governments may also exert coercive isomorphic pressures on organisations through how they structure the transactions within those markets (Greer et al., 2017). For example, the purchaser may specify fixed processes, such as the frequency of appointments or minimum requirements in clients' activity agreements, that providers must adhere to in order to receive payment. Alternatively, the purchaser may leave it to providers to determine what services clients receive, and when, but arrange the payment model so that providers are predominantly paid based on specified outcomes. However, strengthening the performance signals in payment models may generate standardising tendencies of their own by intensifying providers' aversion to risk. This is because they transfer the costs of under-performance onto providers, making experimentation with unproven approaches riskier for organisations.

Importantly, coercive isomorphic pressures are predicted to intensify the more organisations are dependent on another organisation. Greater interdependence generates greater similarity in structure, climate, and behavioural focus' (DiMaggio and Powell, 1983: 154). Again, the modes of transaction in welfare markets, and how they are organised by the purchaser, are likely to have important implications for the degree of organisational inter-dependence in employment services fields. In quasi-markets where users are 'empowered' to purchase services directly through the grant of vouchers, organisations are less financially dependent on the purchasing power of governments than in quasimarkets where governments procure services and 'simply direct the user to the provision it has bought' (Wiggan, 2015: 117). In practice, employment services markets are rarely organised around user-choice. Rather, as in the Australian market, governments often act as the sole purchaser. This would suggest that providers in Australia may be particularly vulnerable to coercive isomorphic pressures because they are competing in a field in which the flow of resources is controlled by a 'monopsony' purchaser. Established providers that have 
organised their businesses around delivering contracts may be especially vulnerable to coercive isomorphic pressures if they have become "'tied into" the field' (Taylor et al., 2016: 265) through resource dependency.

While regulatory and government funding arrangements are 'core drivers' (Frumkin and Galaskiewicz, 2004: 286) of isomorphism, organisations can also be pulled towards convergence by normative and mimetic processes. Normative isomorphic forces result from processes of professionalisation, which DiMaggio and Powell identify in terms of the rise of professional communities and industry associations that serve 'to promulgate normative rules about organisational and professional behaviour' (1983: 152). These 'epistemic communities' (Knill and Balint, 2008: 681) help to diffuse common understandings of policy problems and their solutions within fields. In mimetic isomorphism, organisations model themselves on counterparts that are perceived to be more legitimate or more successful, or they import practices by osmosis through employee transfer. DiMaggio and Powell (1983) predict that mimetic isomorphism will be more prevalent in fields where there is uncertainty over the relationship between means and ends; an inherent feature of the 'complex and multi-dimensional' transactions that occur in welfare markets insofar as they involve 'the provision of sophisticated service activities rather than the relatively basic provision of material commodities with which traditional markets deal' (Bartlett, 1991: 53).

Organisations delivering social services do so under conditions of bounded rationality. The causal effects of particular service inputs on client outcomes are not particularly well understood. Amidst these conditions, the mimetic copying of established processes reduces 'the decision load' (Beckert, 2010: 155) of determining which configuration of practices is likely to fulfil objectives. Organisations strive to ensure their legitimacy by emulation. Not because of any clear evidence that the copied practices will optimise performance but because some options appear to have an established legitimacy (Ashworth et al., 2007). For organisations entering the field, emulation may be a way of more easily fitting the 'administrative categories that define eligibility for public and private grants and contracts' (DiMaggio and Powell, 1983: 153). In this context, the grant of government contracts may structure isomorphic processes by giving key firms recognition and legitimacy, motivating competitors 'to copy aspects of their structure or operating procedures in the hope of obtaining similar rewards' (DiMaggio and Powell, 1983: 153).

\section{Institutional change at the Australian frontline}

Australia was one of the first OECD countries to fully competitively tender its public employment services, which it did under Job Network in May 1998. It was described by the Australian government as 'the most significant reorganisation of labour market assistance arrangements' (quoted in O’Flynn, 2007: 4) since the 1940s 
and, by the OECD, as 'without parallel' internationally (Finn, 2011: 5). According to O'Flynn, 'it was clear that a new era in employment services had begun' (2007: 1). Although Struyven (2014) argues that the transformation of Australia's system in fact unfolded through a more gradual process of institutional layering, displacement and conversion. Indeed, prior to $\mathrm{JN}$, several hundred for-profit and non-profit agencies were licensed to deliver case management to the long-term unemployed under Labor's Working Nation (1994). This reform created a dual system in which the Commonwealth Employment Service continued to deliver services to a proportion of jobseekers, while a new market was created for case management of the long-term unemployed. In this way, market-based administrative principles were 'layered' onto the existing public system setting in motion new institutional logics that would eventually displace the public foundations of the system under the Howard Coalition government.

Under the first JN contract, a mix of over 300 private, community and government-owned providers won contracts to deliver a range of job-matching, job-search training, and intensive assistance services with the non-public providers winning two-thirds of the market (O'Flynn, 2007). Agencies received a combination of service fees and outcome payments that varied depending on the duration that clients were placed into employment or training and which were differentiated according to jobseekers' assessed level of disadvantage. The second JN contract (2001-2003) extended price competition to intensive service provision, and private providers won almost 90 per cent of contracts as the new market competition logic became the system's 'major driving force' (Ramia and Carney, 2000: 66).

The first two JN contracts operated mostly as 'black box' systems in that providers were afforded much leeway to determine the assistance they provided. However, this changed from 2003, when greater specification concerning the content and frequency of services was introduced along with minimum service guarantees. While partly about guaranteeing service quality, this measure was also designed to ensure that jobseekers' mutual obligations were consistently enforced under a new Active Participation model (Considine et al., 2015: 39). Providers were required to document how clients were meeting their conditionality requirements via a new central IT platform. This information could be viewed by agency managers and departmental officials, who exhibited an increased inclination towards recovering payments from providers who were found to have misused their discretion. This heavier regulation was driven by growing evidence that agencies were gaming the system through practices of 'creaming' and 'parking' clients (Considine, 2001), and even 'creating phantom jobs' to collect payments (O'Flynn, 2007: 4).

Another important change was the abandonment of price-competition during tenders. In the face of evidence that agencies' contract bids were 'at a level that was insufficient to ensure proper employment assistance for the most 
disadvantaged' (Thomas, 2007: 8), the government instituted fixed prices and a quarantined pool of funds (the Employment Fund) for purchasing assistance for clients that providers were unable to retain as profit. With price-competition abandoned, past performance became the basis for allocating contracts and market share as determined by a new 'Star Ratings' performance measurement system. This system, which was introduced in 2001 and remains in operation, uses a confidential regression to award each site a performance rating - initially every six months, but now quarterly - that then feeds into providers' overall rating at a region level. It was originally intended as a kind of 'Michelin Guide' (Considine et al., 2015: 38) for signalling providers' relative performance to clients, although it quickly became the key mechanism for awarding contracts and periodically (re)allocating shares of jobseekers within contract regions from low to high-performing providers. Sixty per cent of the agencies awarded contracts in 2003 automatically had their contracts extended based on their Star Ratings. It was at this point in the system's evolution that the government-owned provider collapsed, seemingly unable to compete with the other private agencies that made up the rest of JN. In 2006, less than 10 per cent of contracts were competitvely tendered as JN became consolidated around one hundred 'core providers' (Finn, 2011), all for-profits or not-for-profits.

The marketisation of Australia's employment services was driven by the belief that competition would not only increase efficiency but also promote innovation and tailoring. While the average cost of employment outcomes did decline (Thomas, 2007), JN did not produce the levels of flexibility predicted. Studies suggest that it instead resulted in a quasi-market of agencies focused on survival, and for whom the risk involved in not sticking to beaten paths was 'simply too high' (Bredgaard and Larsen, 2008: 345). Part of the problem related to the purchaser's increasingly prescriptive approach to regulating transactions within the market. Increasing contractual specification and the detailed oversight of providers via the application of IT-based information systems, critics contended, had given rise to an 'inflexible' pattern of outsourced services' (Finn, 2011: 13) where "'personalised service" [was] the exception, rather than the norm' (Marston and McDonald 2008: 265). Considine et al.'s comparative research showed a 'marked increase in the level of routinisation and standardisation at the frontline' (2011: 811) as agencies responded to the intensification of administrative accountability by embracing standardisation 'as a way to minimise risks' (2011: 826). This in turn led to a loss of differentiation between for-profit and not-for-profit providers.

Since JN, there have been by two major re-structures of the Australian system: Job Services Australia (JSA) (2009-15) and Jobactive (2015-2022). JSA was introduced by Labor in 2009, following a review of JN. Major emphases of the reform were to make the system less punitive and to replace JN's “"one size fits all" approach ... with greater flexibility for employment services providers 
to tailor services' (Gillard, 2008). Jobseekers were to become more involved in designing their employment plans, with the new system placing a greater emphasis on 'increasing flexibility... and on providing more integrated and holistic "wrap-around” support' (SSC, 2009: 31). This was accompanied by a partial softening of the compliance framework, as agencies were given more discretion over the tailoring of clients' Job Plans (Ramia and Carney, 2010). The funding model was also adjusted to increase the incentives for agencies to focus on assisting harder-to-help clients, and the performance framework partially revised to move 'away from the "command and control" relationship' that had characterised the later years of JN (Finn, 2011: 20).

The restructure came at considerable transition cost. Approximately 320,000 jobseekers were required to change provider, while agencies who retained a similar market share incured millions in transaction costs associated with the change (Finn, 2011: 17). This points 'to a dilemma in the tendering model' (McDonald and Marston, 2008: 106). To maintain a competitive market, the purchaser needs to continuously generate new tendering processes that, in turn, generate high transaction costs associated with the preparation of tendering documents, assessment of bids and negotiation of contacts. Whereas established providers can deploy the informational advantages and surpluses gained from previous contracts to bid for repeat contracts, new entrants 'must expend resources on market participation and business acquisition costs without any guarantee that contracts can be secured' (Bennett, 2017: 143). There are also the ex-post transaction costs that arise for both the purchaser and providers associated with monitoring the market to mitigate risks of gaming behaviours.

These transaction costs 'are an inescapable by-product of contracting out' (Bredgaard and Larsen, 2008: 345). However, institutional economists argue that they are likely to be especially high in social services markets: where 'a contractor knows the quality of its service is difficult to observe, where a large degree of information asymmetry exists ... and where the assessment of a provider's true additionality is confounded by external factors such as the business cycle or simply demand for labour' (Hill, 2013: 198). To manage these risks, purchasers try to steer agents' behaviours via detailed contractual specification of processes, penalty clauses, and mechanisms for post-contract oversight. But beside the difficulties involved in fully specifying contracts and determining the appropriate balance between price and quality in payment models (Bartlett, 1991; Bredgaard and Larsen, 2008; Bennett, 2017), such a contracting regime is very costly to administer. By the end of JSA, the annual cost of administrating the system was estimated at $A \$ 259.3 \mathrm{~m}$, or 21 per cent of total programme costs (ANAO, 2017).

The high-costs of administering the system, and associated impact on levels of service flexibility, have been a persistent challenge for governments in Australia. In mid-2015, the new Coalition government introduced what it argued was another 'fundamental reform of employment services' (DoE, 2016: 11). It criticised JSA as 
heavily 'constrained by administrative requirements' (DoE, 2016: 9), attributing this to the system's 'limited scope for provider-initiated service design' (DoE, 2016: 9). Accordingly, and like preceeding reforms, a key objective of the reform was to 'reduce service prescription' (DoE, 2015: 1). Providers were permitted to bid on the basis of different service models, in the hope that this would free them 'to deliver flexible solutions tailored to an individual jobseeker's circumstances' (ANAO, 2017: 34). At a more ideological level, the reform also sought to intensify jobseeker activation through strengthening conditionality. Other key changes included the lengthening of contracts to five years and increase in the size of the geographic areas that agencies were awarded contracts for; changes that resembled elements of the UK's Work Programme commissioning model and which were designed to minimise the purchaser's transaction costs through reducing the number of exchange relationships it would need to enter into and monitor (Bennett, 2017). Another parallel with the Work Programme was the restructuring of the pricing mechanism towards Payment-by-Results. The proportion of total provider funding represented by outcome payments increased to more than 50 per cent compared with a third previously (ANAO, 2017: 15).

These changes to how providers were contracted and paid by the purchaser were designed to stimulate greater flexibility. However, by increasing the level of financial risk that providers needed to assume to deliver contracts, they also threatened to reduce diversity by making it harder for smaller, not-for-profit organisations with fewer capital reserves to remain-in or enter the market. Just 44 agencies won contracts. For-profit agencies won more of the maket than before, prompting concerns about 'the ongoing dilution of the not-for-profit difference in the system' (Jobs Australia, 2015a: 3).

\section{The study}

While JSA and Jobactive diverged in their approaches to jobseeker compliance, both reforms constituted attempts to reverse the standardised pattern of service delivery that had developed under JN. This problem of standardisation related to both the administrative, rule-bound approach to case management as well as the loss of differentiation between providers. To consider whether these subsequent reforms have produced substantial change towards a more varied and flexible employment services market or exhibited patterns of institutional closure and inertia, we return to Considine et al.'s (2011) analysis of the impact of ten years of reform on service flexibility at the Australian frontline. That study drew on two waves of survey data collection with frontline staff, firstly between 1996 and 1999, and repeated in 2008, using largely the same instrument. This instrument comprised over 100 questions, principally about: how frontline staff carry-out basic service delivery tasks; the extent to which they use standardised assessment tools and scripted IT-driven processes when working with clients; and the 
TABLE 1. Respondents

\begin{tabular}{lcccc}
\hline & For-profit staff & Not-for-profit staff & Other/unknown & Total \\
\hline 2008 & 392 & 1056 & 64 & 1512 \\
2012 & 316 & 882 & 66 & 1264 \\
2016 & 393 & 799 & 41 & 1233 \\
\hline
\end{tabular}

degree to which they incorporate client-preferences in servicing. That approach, and ability to compare responses between workers in public, for-profit and not-forprofit agencies, enabled a comparison between Australia's partially contractedout system in the late 1990 s and fully privatised system by 2008 , with a dual focus on whether increased marketisation had delivered more flexible services, on the one hand, as well as greater diversity of assistance, on the other. We update that analysis, using data from two further surveys in 2012 and 2016 and benchmarking these against the 2008 findings.

As in 2008, these subsequent surveys were conducted online. In 2012, more than 1200 frontline staff from 26 agencies were surveyed while 1233 respondents from 32 agencies participated in 2016 (Table 1). The data were analysed using SPSS software. Chi-squared and Kruskal-Wallis tests were used to detect differences between survey years when responses were categorical, ordinal or rank order. In cases of numeric responses or continuous variables, ANOVA was used.

Findings from 2012 have previously been reported, suggesting large continuities in frontline practice between JN and JSA (Considine et al., 2014a). With an additional wave of data collection tracking frontline practice under Jobactive, a longer-term assessment of patterns of continuity and change in the degree of 'flexibility' within the Australian quasi-market is now possible. We assess this from multiple perspectives: the level of frontline decision-making (discretion), the level of responsiveness to individual jobseekers (tailoring), and the degree of difference between providers (market diversity). These dimensions are interrelated insofar as a system that encourages tailoring requires that frontline staff have some capacity to act independently and to adjust their approach to the individual. It doesn't automatically follow that frontline autonomy will promote tailoring, since discretion can also be exercised to make work more manageable and in ways that benefit 'the worker rather than the client' (Fletcher, 2011: 447). Nonetheless, a degree of autonomy is a precondition for the possibility of 'contextualised' (Sainsbury, 2017: 64) decision-making that is responsive to the interests of clients. Accordingly, a 'flexible' quasi-market implies high levels of professional discretion, directed toward service tailoring which, in turn, should produce greater variation between providers.

Relying on frontline workers' self-reported understandings of their working conditions as indicators of actual levels of flexibility within the Australian 
TABLE 2. Flexibility and discretion

\begin{tabular}{|c|c|c|c|c|c|}
\hline $\begin{array}{l}\text { Strongly } \\
\text { Agree }\end{array}$ & Agree & Neither & Disagree & $\begin{array}{l}\text { Strongly } \\
\text { Disagree }\end{array}$ & $\begin{array}{c}\text { Mean } \\
\text { rank }\end{array}$ \\
\hline
\end{tabular}

When it comes to day-to-day work I am free to decide for myself what I will do with each client/ job seeker

$\begin{array}{lrrrc}2008(\mathrm{n}=897) & 18.4 \% & 44.1 \% & 14.8 \% & 18.4 \% \\ 2012(\mathrm{n}=852) & 10.6 \% & 49.6 \% & 18.9 \% & 17.6 \% \\ 2016(\mathrm{n}=754) & 9.8 \% & 39.8 \% & 24.0 \% & 21.9 \% \\ & \text { 2008-12: Chi-squared(1) }=4.452 ; \mathrm{P}=0.035 \\ \text { 2012-16: Chi-squared(1) }=13.432 ; \mathrm{P}<0.0001 \\ \text { 2008-16: Chi-squared(1) }=27.722 ; \mathrm{P}<0.0001\end{array}$

My supervisor knows a lot about the work I do day-to-day

$\begin{array}{llrrrrr}2008(\mathrm{n}=888) & 33.3 \% & 48.4 \% & 7.8 \% & 6.8 \% & 3.7 \% & 1198.10 \\ 2012(\mathrm{n}=853) & 25.8 \% & 53.3 \% & 10.0 \% & 7.5 \% & 3.4 \% & 1293.15 \\ 2016(\mathrm{n}=758) & 29.9 \% & 48.0 \% & 10.7 \% & 7.3 \% & 4.1 \% & 1262.25\end{array}$

2008-12: Chi-squared(1) $=9.120 ; \mathrm{P}=0.003$

2012-16: Chi-squared(1) $=0.819 ; \mathrm{P}=0.365$

2008-16: Chi-squared $(1)=3.678 ; \mathrm{P}=0.055$

When I come across something not covered by the procedural guide I refer it to my supervisor

$\begin{array}{lllllrr}2008(\mathrm{n}=887) & 34.5 \% & 56.6 \% & 5.3 \% & 3.2 \% & .5 \% & 1200.65 \\ 2012(\mathrm{n}=851) & 28.8 \% & 59.1 \% & 6.5 \% & 4.9 \% & .7 \% & 1291.54 \\ 2016(\mathrm{n}=755) & 33.6 \% & 52.6 \% & 8.5 \% & 3.6 \% & 1.7 \% & 1251.25\end{array}$

2008-12: Chi-squared(1) $=9.108 ; \mathrm{P}=0.003$

2012-16: Chi-squared $(1)=1.501 ; \mathrm{P}=0.221$

2008-16: Chi-squared(1) $=2.436 ; \mathrm{P}=0.119$

Our computer system tells me what steps to take with clients/job seekers and when to take them

$\begin{array}{lllllll}2008(\mathrm{n}=887) & 5.1 \% & 42.3 \% & 23.8 \% & 23.0 \% & 5.9 \% & 1268.20 \\ 2012(\mathrm{n}=883) & 6.6 \% & 43.8 \% & 24.4 \% & 22.0 \% & 3.2 \% & 1203.92 \\ 2016(\mathrm{n}=736) & 6.7 \% & 41.6 \% & 28.8 \% & 19.8 \% & 3.1 \% & 1208.47\end{array}$

2008-12: Chi-squared(1) $=3.918 ; \mathrm{P}=0.048$

2012-16: Chi-squared $(1)=0.020 ; \mathrm{P}=0.887$

2008-16: Chi-squared $(1)=3.203 ; \mathrm{P}=0.074$

Note: Significance tests have been conducted on mean rank scores, which also show the direction of change.

welfare market is not without problems. There is a risk that the data could be subject to recall bias or skewed by respondents' overly optimistic assessment of their own agency as workers. Nevertheless, we expect any such effects to be generalised across the sample, both within and between survey years, and therefore unlikely to undermine the value of the comparative analysis over time.

\section{Findings}

Table 2 reports several measures used to track changes in frontline discretion over time. In contrast to the intent behind the JSA and Jobactive reforms, these data suggest a moderate reduction in levels of frontline autonomy since JN. 
Frontline staff remain under high supervisory oversight, and there is evidence of increased reliance on IT systems and standardised protocols to guide their decision-making. This is reflected in the decline in the proportion of participants who agree or strongly agree that they are free to decide for themselves what to do with clients. This has fallen from just under 63 per cent in 2008 to below 50 per cent in 2016. This change is statistically significant and is mirrored in participants' responses concerning the extent to which their decision-making is mediated by computers. In 2008, 47 per cent of respondents indicated that their computer system told them what steps to take with jobseekers and when to take them. Despite the considerable criticisms directed at the transformation of case management into a form of 'screen-level bureaucracy' under JN (Marston and McDonald, 2008), this proportion increased to above 50 per cent following the JSA reforms. This change is statistically significant. Although there has been a marginal decline in the proportion reporting such a reliance on computer-based decisions since, this latter decrease is not statistically significant. The data also show no statistically significant easing in the level of supervisory oversight of frontline staff by agency managers. Between surveys, there have been few significant changes in participants' responses concerning either the extent to which their supervisor knows a lot about the work they do from day-to-day, or their tendency to defer decisions to their supervisor in cases not covered by procedural guidelines. Although the proportions agreeing or strongly agreeing that (a) they defer to their supervisors when faced with issues not covered by the procedural guide, or that (b) their supervisor knows a lot about their daily work, have declined from 91 per cent and 82 per cent respectively in 2008 to 86 per cent and 78 per cent respectively in 2016 , these changes are not statistically significant. This indicates the continuation of a procedural approach to decision-making based on following scripts and escalating more complex cases to line managers (Considine and Lewis, 1999).

This pattern is also observed in the data in Table 3, which track a range of measures concerning whether client servicing is driven by standardised routines or is responsive to individual choice. Again, we find no evidence of a discernible reversal in the pattern of routinised frontline work observable under JN. Indeed, the proportion who report that the IT system they use dictates how they do their jobs 'to a large extent', and that their own judgement is 'not at all' influential in determining what activities are recommended, have both increased since 2008 . It must be noted, however, that these changes involve relatively marginal increases, and are not statistically significant. What is statistically significant is the increase in the proportion who indicate that the decisions they make about clients are determined 'to a great deal' by standard programme rules, which has steadily risen from 18 per cent in 2008 to 27 per cent in 2012 to 31 per cent in 2016. Although there has been a somewhat surprising decrease in the proportion indicating that answers to standardised assessment questions are influential in 
TABLE 3. Flexibility and tailoring

\begin{tabular}{|c|c|c|c|c|c|c|c|c|}
\hline & $\begin{array}{l}\text { 1.A small } \\
\text { extent }\end{array}$ & 2 & 3 & 4 & 5 & 6 & $\begin{array}{l}\text { 7.A large } \\
\text { extent }\end{array}$ & $\begin{array}{l}\text { Mean } \\
\text { Rank }\end{array}$ \\
\hline \multicolumn{9}{|c|}{ The extent to which you feel the IT system you use dictates how you do your job? } \\
\hline $2008(n=1032)$ & $2.0 \%$ & $5.4 \%$ & $8.6 \%$ & $14.6 \%$ & $20.8 \%$ & $25.7 \%$ & $23.0 \%$ & 1354.34 \\
\hline $2012(\mathrm{n}=887)$ & $1.8 \%$ & $4.0 \%$ & $9.8 \%$ & $19.0 \%$ & $22.3 \%$ & $20.5 \%$ & $22.7 \%$ & 1305.63 \\
\hline \multirow[t]{6}{*}{$2016(789)$} & $2.3 \%$ & $7.1 \%)$ & $13 \cdot 3 \%$ & $13 \cdot 3 \%$ & $18.0 \%$ & $20.9 \%$ & $25.1 \%$ & 1297.72 \\
\hline & \multirow{3}{*}{\multicolumn{8}{|c|}{$\begin{array}{l}\text { 2008-12: Chi-squared }(1)=2.198 ; P=0.138 \\
\text { 2012-16: Chi-squared }(1)=0.096 ; P=0.757 \\
\text { 2008-16: Chi-squared }(1)=2.261 ; P=0.133\end{array}$}} \\
\hline & & & & & & & & \\
\hline & & & & & & & & \\
\hline & 1.Very little / & & & & & & 7.A great & Mean \\
\hline & None & 2 & 3 & 4 & 5 & 6 & deal & Rank \\
\hline
\end{tabular}

To what extent are the decisions you make about your clients determined by standard programme rules and regulations?

$\begin{array}{lllllllll}2008(\mathrm{n}=933) & .6 \% & 1.6 \% & 3.8 \% & 11.3 \% & 26.5 \% & 38.0 \% & 18.2 \% & 1256.61 \\ 2012(\mathrm{n}=893) & .2 \% & .8 \% & 3.2 \% & 17.9 \% & 24.3 \% & 26.4 \% & 27.1 \% & 1282.69 \\ 2016(\mathrm{n}=799) & .5 \% & .4 \% & 2.3 \% & 12.0 \% & 22.7 \% & 31.4 \% & 30.8 \% & 1412.73\end{array}$

2008-12: Chi-squared(1) $=0.428 ; \mathrm{P}=0.513$

2012-16: Chi-squared $(1)=12.411 ; \mathrm{P}<0.0001$

2008-16: Chi-squared $(1)=20.744 ; \mathrm{P}<0.0001$

How much does your agency emphasise giving clients more CHOICE about the services they receive? $\begin{array}{llrrrrrrr}2008(\mathrm{n}=1006) & 1.9 \% & 7.7 \% & 11.8 \% & 22.8 \% & 26.7 \% & 18.9 \% & 10.2 \% & 1318.87 \\ 2012(\mathrm{n}=897) & 1.7 \% & 5.9 \% & 8.2 \% & 27.3 \% & 25.8 \% & 16.3 \% & 14.8 \% & 1387.08 \\ 2016(\mathrm{n}=803) & 4.0 \% & 5.6 \% & 10.6 \% & 23.2 \% & 24.3 \% & 19.1 \% & 13.3 \% & 1359.36\end{array}$

2008-12: Chi-squared(1) $=3.786 ; \mathrm{P}=0.052$

2012-16: Chi-squared(1) $=0.551 ; \mathrm{P}=0.458$

2008-16: Chi-squared $(1)=1.240 ; \mathrm{P}=0.265$

\begin{tabular}{|c|c|c|c|c|c|c|}
\hline & $\begin{array}{l}\text { Strongly } \\
\text { Agree }\end{array}$ & Agree & Neither & Disagree & $\begin{array}{l}\text { Strongly } \\
\text { Disagree }\end{array}$ & $\begin{array}{l}\text { Mean } \\
\text { Rank }\end{array}$ \\
\hline \multicolumn{7}{|c|}{ All my clients receive a similar service } \\
\hline $2008(n=884)$ & $24.5 \%$ & $54.1 \%$ & $6.7 \%$ & $12.2 \%$ & $2.5 \%$ & 1206.47 \\
\hline $2012(\mathrm{n}=835)$ & $21.1 \%$ & $54.0 \%$ & $9.6 \%$ & $12.8 \%$ & $2.5 \%$ & 1267.82 \\
\hline \multirow[t]{3}{*}{$2016(\mathrm{n}=739)$} & $25.2 \%$ & $50.7 \%$ & $11.9 \%$ & $10.3 \%$ & $1.9 \%$ & 1213.75 \\
\hline & \multicolumn{6}{|c|}{$\begin{array}{l}\text { 2008-12: Chi-squared }(1)=3.879 ; \mathrm{P}=0.049 \\
\text { 2012-16: Chi-squared(1) }=2.703 ; \mathrm{P}=0.100 \\
\text { 2008-16: Chi-squared }(1)=0.050 ; \mathrm{P}=0.823\end{array}$} \\
\hline & \multicolumn{2}{|c|}{$\begin{array}{l}\text { Not at all } \\
\text { influential }\end{array}$} & $\begin{array}{l}\text { newhat } \\
\text { uential }\end{array}$ & $\begin{array}{c}\text { Quite } \\
\text { influential }\end{array}$ & $\begin{array}{c}\text { Very } \\
\text { influential }\end{array}$ & $\begin{array}{c}\text { Mean } \\
\text { rank }\end{array}$ \\
\hline
\end{tabular}

How influential are: ... answers to a standard set of assessment questions in determining what activities are recommended for each job seeker?

$\begin{array}{lrrrrr}2008(\mathrm{n}=1155) & 7.8 \% & 40.0 \% & 34.2 \% & 18.0 \% & 1638.24 \\ 2012(\mathrm{n}=989) & 9.7 \% & 45.8 \% & 32.8 \% & 11.7 \% & 1487.93 \\ 2016(\mathrm{n}=921) & 11.7 \% & 46.5 \% & 28.8 \% & 13.0 \% & 1449.42\end{array}$

2008-12: Chi-squared(1) $=17.858 ; \mathrm{P}<0.0001$

2012-16: Chi-squared $(1)=1.158 ; \mathrm{P}=0.282$

2008-016: Chi-squared $(1)=25.865 ; \mathrm{P}<0.0001$ 
Overall, what emerges is a picture in which frontline workers' own professional discretion has narrowed while, simultaneously, jobseekers' preferences have paradoxically gained in influence. This may suggest that the application of programme rules has become a more focal task of frontline work and is consistent with the ideological elements of the Jobactive reforms on introducing stronger mutual obligation requirements' (DoE, 2016: 9). But within this process of ensuring that jobseekers are meeting requirements, clients are being given some choice over how to comply (or which programmed activities to undertake). This might be characterised as a form of shallow tailoring: client choice influences what activities are undertaken but the menu jobseekers can select from, and the time when activities must be undertaken, is bounded by programme rules (compare Sainsbury, 2017: 64).

What is perhaps most remarkable about these data on frontline discretion and tailoring is the absence of significant patterns of change in the levels of flexibility since JN. To consider this issue in more detail, we further analysed the data using an inter-sectorial comparative approach. Consistent with previous data analysis methods used to consider levels of convergence within the sector, we compared the responses of staff employed by for-profit and not-for-profit providers on 113 different variables (Table 4). Already, in 2008, our data had suggested isomorphic pressures in the Australian quasi-market insofar as the JN experiment did not lead to an industry of service innovators but a 'herd' of profit maximisers ... who embrace standardisation of services as a way to minimise risks' (Considine et al., 2011: 826). However, repeating this test on the 113 items used across all waves of data collection since 2008 shows a dramatic intensification in the level of organisational convergence since JN. Whereas 24 statistically significant differences were observed between the for-profit and not-for-profit sectors in 2008, this reduced to 8 under JSA and 11 under Jobactive. That is, on almost 90 per cent of items, we found no statistically significant difference between the responses of for-profit and not-forprofit agency staff. Of the differences that remained, several related to workers' level of contact with external agencies and stakeholders. But on items related to agencies' use of sanctions, time spent on various job tasks (e.g. documenting compliance, in contact with jobseekers), and level of frontline discretion, the number of statistically significant differences between the responses of for-profit and not-for-profit agency staff substantially reduced post-JN.

By 2016, any lingering differences between for-profit and not-for-profit agency workers in terms of their perceptions of jobseekers and willingness to apply a standardised 'work first' model of activation had entirely disappeared. Similarly, the value-orientations of for-profit and not-for-profit staff, and their beliefs about the key objectives of their jobs, had become almost indistinguishable. Whereas the responses of frontline staff working in different sectors significantly differed along five variables related to their goal orientation and 
TABLE 4. Statistically significant differences in response between respondents from for-profit and not-for-profit agencies

$20082012 \quad 2016$

\section{Caseload and time spent on tasks}

Caseload size

Number of jobseekers seen per day

Proportion of clients followed 'somewhat'

Time spent in direct contact with jobseekers

... working with employers

... on contract compliance

$\begin{array}{lll} & & \\ \mathrm{X} & & \mathrm{X} \\ & \mathrm{X} & \\ & \mathrm{X} & \\ \mathrm{X} & \mathrm{X} & \\ \mathrm{X} & & \end{array}$

\section{Working with other organisations}

Level of contact with another office in this organisation

... with officials from a government department

... with employers

... with schools and universities

Willingness to assist employees from other organisations

\section{Sanctioning}

Reasons for sanctioning: when a jobseeker fails to contact our office

Reasons for not sanctioning: The jobseeker is normally a good client ...

Whether agencies encourage staff to be lenient in the use of sanctions

No. of jobseekers sanctioned in previous two weeks

\section{Work-first orientation}

Agency goal: to help jobseekers get a job quickly OR raise education levels

Management advice: whether clients should take low-paying, entry jobs or wait for better opportunities

\section{Frontline autonomy}

Decisions are determined by standard programme rules and regulations

Supervisor knows a lot about the work they day each day

Use of personal judgement to decide what to do

\section{Priorities and goal orientation}

Job objective: maximise financial outcomes

Job objective: maximise number of clients off benefits

Consider themselves an advocate for clients

Awareness that organisation pays attention to the income they generate

Office work priorities

Personal work priorities

\section{Perceptions of jobseekers}

Whether jobseekers are on benefits due to lack of effort

$\%$ of jobseekers who would rather be on benefits than work

Believe that many clients will never find open employment

Governments should do more to help jobseekers

$\mathrm{X}$

$\mathrm{X}$

$\begin{array}{lll}\text { X } & & \\ & \mathrm{X} & \mathrm{X} \\ \mathrm{X} & & \mathrm{X}\end{array}$

$\mathrm{X}$

$\mathrm{X}$

$\mathrm{X}$

$\mathrm{X} \quad \mathrm{X}$

$\mathrm{X}$

$\mathrm{X}$

$\mathrm{X}$

$\mathrm{X}$

$\mathrm{X} \quad \mathrm{X}$

$\mathrm{X}$

$\mathrm{X}$

$\mathrm{X}$

$\mathrm{X}$

$\mathrm{X}$

$\mathrm{X}$

$\mathrm{X}$

$\mathrm{X}$

$\mathrm{X}$

$\mathrm{X}$

$\mathrm{X}$

$\mathrm{X}$

Willingness to exert extra effort on
Satisfaction with pay and conditions

\section{Miscellaneous}

Feel informed about policies and procedures

Feel informed about how well their job is done

Views about system effectiveness in moving people off benefits

Influence of availability of labour market programme vacancies on what activities are recommend Total

\section{x}

$x$

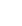
x $\mathrm{x}$
$\mathrm{x}$ 
work priorities in 2008, this narrowed to just one remaining difference by 2016 . This, along with the homogenisation in frontline workers' beliefs about jobseekers, points to strong consolidation in the Australian system over the past decade. This consolidation is particularly striking insofar as the 'core' of organisational cultures and value systems is thought to be less susceptible to influences from the institutional environment than the 'periphery' of organisational processes (Ashworth et al., 2007: 171).

\section{Discussion and Conclusion}

We have assessed whether the Australian quasi-market has evolved into a more flexible system across three dimensions: frontline discretion, tailoring, and market diversity. We find no significant pattern of change between JN, JSA, and Jobactive in levels of standardisation or supervisory oversight at the frontline and, if anything, further erosion of frontline discretion and the intensification of prescriptive approaches to decision-making. This is despite repeated governments explicitly stating that one of their key reform priorities was increasing service diversity and enabling better-tailored services. The diffusion of case management practices and value-orientations across organisations has also rapidly accelerated, with the surviving for-profit and not-for-profit providers much more alike than under JN. What is notable about this consolidation is its direction, with providers converging on a standardised model of frontline practice rather than the enhanced flexibility anticipated by the reforms. This consolidation might be described as a form of non-compliant convergence (Ashworth et al., 2007) insofar as providers have resisted conforming to norms of flexibility promoted by the purchaser.

What are the mechanisms driving this heavy consolidation within the Australian employment services field? Our data do not allow us to establish these conclusively since we only track reported changes in frontline practice and organisation models over many years of complex institutional changes, not the causal mechanisms propelling these changes. Moreover, we cannot discount the role of activation policy reforms, such as the strengthening of mandatory job search and other conditionality (e.g. Work-for-the-Dole) requirements under later iterations of the system in 'crowding out' possibilities for service flexibility through limiting opportunities for providers to deviate from implementing standardised 'work first' models. That is, the increasing standardisation of the Australian employment services field may have been driven, at least in part, 'from the top down' through policy effects on frontline practice and reduced possibilities for referring clients to alternative employability programmes and flanking social services (see, in relation to similar patterns in the UK, Fuertes and Lindsay, 2016: 540). 
Nevertheless, several additional factors may plausibly have contributed to the deepening institutional inertia in additional to these policy dynamics. Some of these relate to the mimetic and normative isomorphic pressures that take hold within organisational fields over time, such that 'the more mature an organisational field, the more likely it is to be heavily "structurated" by institutional norms and rules' (Ashworth et al., 2007: 167). As institutional theorists observe, information flows and interactions between organisations increase as organisational fields become more developed, along with socialisation processes via the establishment of professional communities (DiMaggio and Powell, 1983: 148). Employee transfer may also become more prevalent, further perpetuating 'adherence to legitimised organisational forms' (Kitchener, 1998: 75). Here previously reported survey data show an upward trend in the proportion of staff with over 5 years' experience working in the field, from 31 per cent in 2008 (Considine et al., 2015) to 48 per cent in 2016 (Lewis et al., 2016). Yet the proportion who have been with their employer for over 5 years has only marginally increased, from 17 to 19 per cent.

Other explanatory factors are more specific to the modes (and terms) of transaction within the Australian welfare market, and how these have been continuously adjusted by the purchaser to deal with some of the implementation challenges that arise when trying to achieve public policy objectives via the NPM instruments of competitive tendering and contract regulation. As Breedgaard and Larsen argue, striking the right balance 'between the logic of the market and social goals' remains a constant challenge for governments when contracting social services from market providers (2007: 292). Authorities try 'to let the market work on its own premises' to enhance efficiency but information asymmetry problems and the high dergee of uncertainty over the relationship between inputs and outputs makes the risks of gaming behaviours and other unintended consequences especially high. As we have seen in Australia, 'constant adjustments and changes to the tendering system' (Bredgaard and Larsen, 2007: 293) are needed to cope with the inherent tensions between equity and efficiency in welfare markets. Reviewing these reform dynamics, we can see how features of the structuring of quasi-market transactions by the public purchaser intersect with other isomorphic pressures to amplify tendencies towards inertia within the Australian welfare market.

The first of these is the displacement of 'black box' approaches with forms of 'hard contracting' (van Berkel, 2014: 192) underpinned by stronger forms of administrative accountability. These include the specification of detailed procedural guidelines by the purchaser, regular caseload and compliance audits, and the introduction of mandatory IT-based case management systems. Under JSA, for example, more than 3,000 pages of departmental guidelines applied to providers (ANAO, 2017) who faced the threat of payment recovery penalties, the imposition of additional reporting requirements, and potential exclusion from future business if they were found to be in breach 
of contractual clauses or guidelines. While the Jobactive contract gave providers more leeway to develop their own models, these had to cohere with prescribed universal service guarantees. Additionally, frontline work continued to be guided by over 30 different guideline documents covering issues such as the circumstances under which jobseekers may be suspended, what activities to include in Job Plans, and allowable employment fund expenditure (ANAO, 2017). These guidelines and formalised service guarantees powerfully signal the institutional legitimacy of various organisational practices, while the intensive monitoring of providers for breaches of contractual compliance exerts coercive isomorphic pressures on organisations to follow prescribed processes.

The reluctance of the purchaser to abandon this micro-management of providers is understandable given the political risks associated with contract gaming. But, in addition to increasing the transaction costs of managing the market, the evidence suggests that it locks-in 'a focus on transactions' (Jobs Australia, 2018: 9) and narrow approach to client-servicing based around reducing providers' exposure to audit risk. This was illustrated by Senate Inquiry testimony about a reluctance across the sector to spend Employment Fund resources on anything beyond a narrow range of items, which agency managers attributed to consultants' fear of putting themselves and their organisation 'at risk of recovery funds and compliance action' (SEERC, 2019: 81).

Elements of the performance framework applied by the purchaser further reinforce this risk-aversion among providers; most notably, the Star Ratings system which is used to periodically re-allocate market share, in terms of the proportion of jobseekers within a contract area, from low to high-performing providers. With providers' short-term survival dependent on achieving 3-stars or above, the incentive is 'to focus on quantum rather than quality of outcomes' (NESA, 2018: 17) and to compete 'to out-do each other' (Jobs Australia, 2018: 26) at delivering the same services rather than experimenting with innovations that may put them 'at risk in the next business allocation' (Jobs Australia, 2015b: 3). This short-term orientation is further reinforced by the pricing signals in the payment model, which have been reconfigured towards Payment-by-Results. This has shifted more financial risk onto providers, whose viability has become increasingly dependent on maximising the number of employment outcomes they can achieve at minimal cost. In other jurisdictions, providers have responded to these downward cost pressures by increasing caseload sizes and employing 'fewer and less qualified staff' (Greer et al., 2017: 165). But increasing the outcomes incentives in the payment model also risks further contributing to standardisation through the exclusion of smaller, not-for-profits, with fewer capital resources. This stems from how results-based payment models require agencies to finance the establishment of human and capital infrastructure on the basis of estimated, but uncertain, outcome payments. When the payment 
model incorporates only limited administration fees, as under Jobactive, the available fixed funding may be 'insufficient to cover the administrative cost of managing the Deed' (NESA, 2018: 14) or the capital investment required to establish service infrastructure. It is a problem that is compounded by the trend towards larger, longer contracts negotiated with fewer agencies given how these increase the size of the geographic areas across which agencies must deliver services.

As these examples show, how transactions are configured by the purchaser in terms of the pricing signals in payment models, the size of the contract areas, and the level of administrative requirements written into contract deeds, can reinforce broader isomorphic pressures within employment services fields through, among other things: increasing entry barriers, intensifying providers' risk-aversion, and incentivising a focus on low-cost service delivery models. These organisational field and transaction dynamics intersect to make quasimarkets in employment services vulnerable to consolidation around a group of 'insider firms' (Bennett, 2017: 144). Whether Australia has reached such a tipping point is unclear, although the degree of organisational convergence since JN suggests it may not be far off. The degree to which the Australian experience can be generalised to other countries also requires further work. It may be that some of the influences driving institutional inertia in the Australian market can be mitigated through alternative organisations of the transactions in welfare markets, such as replacing the monopsony purchasing of competitive tendering with direct purchasing of services by voucher-holding clients.

\section{Acknowledgments}

This work was funded by an Australian Research Council Linkage Grant (LP150100277), supported by our industry partners Jobs Australia, the National Employment Services Association, and Westgate Community Initiatives Group. The authors thank the ARC and our industry partners for their support, in addition to all the employment services providers and many frontline staff who took time out of their busy day to participate in this research.

\section{References}

Ashworth, R., Boyne, G. and Delbridge, R. (2007), 'Escape from the iron cage? Organisational change and isomorphic pressures in the public sector', Journal of Public Administration Research and Theory, 19, 1, 165-87.

Australian National Audit Office (ANAO) (2017), Jobactive: Design and monitoring. Canberra: Commonwealth of Australia.

Bartlett, W. (1991), 'Quasi-markets and contracts: A markets and hierarchies perspective on NHS reform', Public Money and Management, 11, 3, 53-61.

Beckert, J. (2010), 'Institutional isomorphism revisited: Convergence and divergence in institutional change', Sociological Theory, 28, 2, 150-66.

Bennett, H. (2017), 'Re-examing british welfare-to-work contracting using a transaction cost perspective', Journal of Social Policy, 46, 1, 129-48. 
Bredgaard, T. and Larsen, F. (2007), 'Implementing public employmnet policy: What happens when non-public agencies take over?', International Journal of Sociology and Social Policy, 27, 7/8, 287-300.

Bredgaard, T. and Larsen, F. (2008), 'Quasi-markets in employment policy: Do they deliver on promises?', Social Policy and Society, 7, 3, 341-52.

Considine, M. (2001), Enterprising states: The public management of welfare-to-work, Cambridge: Cambridge University Press.

Considine, M. and Lewis, J.M. (1999), 'Governance at ground level: The frontline bureaucrat in the age of markets and networks', Public Administration Review, 59, 6, 467-48o.

Considine, M., Lewis, J.M. and O'Sullivan, S. (2011), 'Quasi-markets and service delivery flexibility following a decade of employment assistance reform in Australia', Journal of Social Policy, 40, 4, 811-33.

Considine, M., Lewis, J.M., O'Sullivan, S. and Sol, E. (2015), Getting welfare to work: Street-level governance in Australia, the UK, and the Netherlands. New York: Oxford University Press.

Considine, M., O'Sullivan, S. and Nguyen, P. (2014a), 'New public management and welfareto-work in Australia: comparing the reform agendas of the ALP and Coalition', Australian Journal of Political Science, 49, 3, 469-85.

Considine, M., O'Sullivan, S. and Nguyen, P. (2014b), 'Governance, boards of directors and the impact of contracting on not-for-profits organisations: an Australian study', Social Policy and Administration, 48, 2, 169-187.

Considine, M., O'Sullivan, S. and Nguyen, P. (2018), 'The policymaker's dilemma: the risks and benefits of a 'black box' approach to commissioning active labour market programmes', Social Policy and Administration, 52, 1,. 229-51.

Department of Employment (DoE) (2015), Evaluation strategy for jobactive. Canberra: Australian Government. URL: https:/docs.employment.gov.au/system/files/doc/other/ evaluation_strategy_for_jobactive.pdf Accessed 15/1/2019.

Department of Employment (2016), Employment services 2015 regulation impact statement. Canberra: Australian Government. URL: http://ris.dpmc.gov.au/2016/02/23/employmentservices-2015/ Accessed 2/3/16.

DiMaggio, P.J. and Powell, W.W. (1983), 'The iron cage revisited: Institutional isomorphism and collective rationality in organisational fields', American Sociological Review, 48, 2, 147-60.

Finn, D. (2011), Job Services Australia: Design and implementation lessons for the British context. London: Department for Work and Pensions.

Finn, D. (2012), Subcontracting in public employment services: The design and delivery of 'outcome based' and 'black box' contracts. Brussels: European Commission.

Fletcher, D.R. (2011), 'Welfare reform, jobcentre plus and the street-level bureaucracy: Towards inconsistent and discriminatory welfare for severely disadvantaged groups', Social Policy and Society, 10, 4, 445-58.

Frumkin, P. and Galaskiewicz, J. (2004), 'Institutional isomorphism and public sector organisations,' Jounral of Public Administration Research and Theory, 14, 3, 283-307.

Fuertes, V. and Lindsay, C. (2016), 'Personalisation and street-level practice in activation: The case of the UK's work programme', Public Administration, 94, 2, 526-41.

Gillard, The Hon. Julia. (2008), More flexible, better targetted employment services. Canberra: Australian Government. URL: https://ministers.jobs.gov.au/gillard/more-flexible-bettertargeted-employment-services Accessed 14/1/2019.

Greer, I., Breidahl, K.N., Knuth, M. and Larsen, F. (2017), The marketisation of employment services: The dilemmas of Europe's work-first welfare states: Oxford: Oxford University Press.

Hill, J.C. (2013), 'The marketisation of employment services and the British work programme', Competition and Change, 17, 2, 197-207.

Jobs Australia (2015a), State of play: Jobactive employment services 2015-2020 tender results. URL: https://www.ja.com.au/sites/default/files/final_sop_-_es_2015-2020_tender_results. pdf Accessed 9/5/2016.

Jobs Australia (2015b), Submission on the competition policy review final report. Melbourne: Jobs Australia. 
Jobs Australia (2018), Submmision to senate inquiry into the appropriateness and effectiveness of the objectives, design, implementation and evaluation of jobactive. Melbourne: Jobs Australia.

Kitchener, M. (1998), Quasi-market transformation: An institutionalist approach to change in uk hospitals. Public Administration, 76:Spring, 73-95.

Knill, C. and Balint, T. (2008), 'Explaining variation in organisational change: The reform of human resource management in the European Commission and the OECD', Journal of European Public Policy, 15, 5, 669-90.

Lewis, J.M., Considine, M., O'Sullivan, S., Nguyen, P. and M. (2016), From entitlement to experiment: the new governance of welfare to work - Australian report back to industry partners. Melbourne: University of Melbourne. URL: https://arts.unimelb.edu.au/_ data/assets/pdf_file/oo10/2165878/2016-Australian-Industry-Report.pdf Accessed 18/7/ 2018.

Marston, G. and McDonald, C. (2008), 'Feeling motivated yet? Long-term unemployed people's perspectives on the implementation of workfare in Australia', Australian Journal of Social Issues, 43, 2, 255-69.

McDonald, C. and Marston, G. (2008), 'Re-visiting the quasi-market in employment services: Australia's Job Network', Asia Pacific Journal of Public Administration, 30, 2, 101-17.

NESA (2018), Nesa's response to the senate inquiry into the appropriateness and effectivesnnes of the objectives, design, implementation and evaluation of jobactive. Melbourne: National Employment Services Association.

O’Flynn, J. (2007), Measuring performance in Australia's Job Network: Part A. Melbourne: the Australia and New Zealand School of Government. URL: https://www.anzsog.edu.au/ preview-documents/case-study-level-1/185-measuring-performance-in-australia-s-jobnetwork-a-2007-37-1/file Accessed 2/4/19.

Ramia, G. and Carney, T. (2000), 'Contractualism, managerialism and welfare: The Australian experiment with a marketised employment services network', Policy and Politics, 29, 1, $59-83$.

Ramia, G. and Carney, T. (2010), 'The Rudd government's employment services agenda: Is it post-NPM and why is that important?', Australian Journal of Public Administration, 69, $3,263-73$.

Sainsbury, R. (2017), 'Activation in the UK: The frontline and the "black box" of employment service provision', van Berkel, R., Caswell, D., Kupka, P. and F. Larsen [Eds] Frontline delivery of welfare-to-work policies in europe: Activating the unemployed. New York: Routledge.

Senate Education and Employment References Committee (SEERC) (2019), Jobactive: Failing those it is intended to service. Canberra: Commonwealth of Australia.

Senate Standing Committee (SSC). (2009), DEEWR tender process to award employment services contracts. Canberra: Commonwealth of Australia.

Struyven, L. (2014), 'Varieties of market competition in public employment services: a comparision of the emergence and evolution of the new system in Australia, the Netherlands and Belgium', Social Policy and Administration, 48, 2, 149-68.

Taylor, R., Rees, J. and Damm, C. (2016), 'UK employment services: Understanding provider strategies in a dynamic strategic action field,' Policy and Politics, 44, 2, 253-67.

Thomas, M. (2007), A review of developments in the Job Network. Canberra: Parliament of Australia. URL: https://www.aph.gov.au/About_Parliament/Parliamentary_Departments/ Parliamentary_Library/pubs/rp/RPo708/o8rp15 Accessed 16/3/16

van Berkel, R. (2014), 'Quasi-markets and the delivery of activation: A frontline perspective', Social Policy and Administration, 48, 2, 188-203.

Wiggan, J. (2015), 'Varieties of marketisation in the UK: Examining divergence in activation markets between Great Britain and Northern Ireland 2008-2014', Policy Studies, 36, 2, 115-32. 